\title{
Cyber Corporate Social Responsibility Communication: Content Analysis on The Official Website of AQUA Group Company
}

\author{
Lenny Merantyca ${ }^{1, *}$, Dini Salmiyah Fithrah Ali \\ ${ }^{1,2}$ Telkom University, Bandung \\ Email: ${ }^{1}$ merantycalenny@gmail.com; ${ }^{2}$ dinidjohan@gmail.com \\ *corresponding author
}

\author{
Keywords: \\ Conten Analysis, CSR \\ Communication, Cyber CSR \\ Official Website
}

\begin{abstract}
The importance of extensive CSR communication is maintained to create a reputation and maintain long-term corporate sustainability. Thus, CSR communication needs to be maintained optimally and comprehensive in a sustainable way to help corporations increase its reputation in the stakeholder's perception and avoid the crisis. Development of cyber information technology makes it easier for stakeholders to gain access to CSR communication, including the use of official websites as accurate as CSR incomes. The study aims to find out how the CSR cyber-communications company AQUA Group activity through official websites. The study studied CSR message content analysis, CSR information presentation, and CSR communication patterns formed by AQUA Group through official websites. The study employed qualitative method of content analysis with a post positivism paradigm. Data collection was done with documentation study techniques that fit the research purposes. The results shows that the content of the CSR's cyber message has been communicated not to refer to the principle of transparency to the content of the internal group's message on employment issues. The CSR's cyber information presentation suggests the AQUA Group has a high level of interactivity on the information fulfillments facility, but it has a low rate of accessibility. The CSR's cyber communication pattern that AQUA Group used a symmetrical two-way communication pattern (the two way symmetrical) by building on stakeholder relationships.
\end{abstract}

Copyright (C) 2021 Channel Jurnal Komunikasi. All right reserved.

\section{INTRODUCTION}

The developments in the current business worldview, especially business's subject demand that companies increase their attention to create innovations to the social environment in order to maintain a sustainable existence. The Company as a business's subject is obliged to determine its policies to follow the goals and values that exist in society as a form of business ethics and corporate social responsibility in the act of social care towards the community. The importance of carrying out social responsibility or better known as Corporate Social Responsibility (CSR) is written in Law No. 40 of 2007 on Limited Liability Companies Article 74 paragraph (1) mentioning "Companies conducting their business activities in the field and/or related to natural resources are obliged to carry out social and environmental responsibilities". With the above legislation states that CSR activities are mandatory activities that must be carried out by a business entity or company on an ongoing basis.

According to Butterick (2012:95) in his book entitled "Introduction of Public Relations Theory and Practice" explains that one of the things the company has done to improve its reputation is to conduct Corporate Social Responsibility (CSR) programs. It is understandable that the implementation of CSR is well managed to help the company to maintain its reputation in the eyes of stakeholders by conducting useful and valuable programs. CSR implementation must have the full support of shareholders and stakeholders in order to avoid threats and crises so that the implementation must be formulated with a mature strategy in accordance with the company's vision and mission. Therefore, the company needs to communicate information on the activities of a company to be an assessment for all stakeholders of the company, especially on the implementation of CSR activities. 
Rusdianto (2013:21) that "CSR communication is a manifestation of the company's efforts in conveying messages related to the company's commitments, policies, programs and performance in economic, environmental, and social pillars to stakeholders". CSR communication as a form of corporate communication strategy in realizing information disclosure to facilitate stakeholders and shareholders to see and respond to csr implementation that has been done. CSR communication must be oriented towards global reporting initiative (GRI) standards in maintaining mandatory sustainability. GRI standard is a CSR communication standard that guarantees the quality of sustainability reporting information in accordance with CSR activities using indicator 26000 (https://majalahcsr.id/sustainability-reporting). CSR communication to stakeholders benefits the company's image and ideally, provides access to stakeholders to be able to verify, and provide input or criticism for future program development" (Rusdianto, 2013:80).

AQUA Group is one of the companies as a business that pay special attention to the importance of CSR communication. Troy Pantouw as Coporate Communication AQUA Group stated in the company's news publication that the importance of transparent and accountable CSR communication can improve the company's reputation (https://aqua.co.id/).

Transparency of AQUA Group CSR communication as a tangible manifestation of the company building stakeholder trust. The transparency of communication of CSR message content becomes an important value for stakeholders and the public for the openness from the information in exposing all corporate programs that can be accounted for, especially related to CSR practices. The transparency of CSR practices conducted by AQUA Group earned the company A B-Corp Certification award for best practices and compliance with the highest standards of corporate performance. AQUA Group is the pioneer of the first bottled water business in Indonesia to become the first Fast Moving Consumer Good (FMCG) company to get the certification (https://aqua.co.id/). This is makes AQUA to continue its commitment to lead sustainable business by inspiring and facilitating acts of kindness through three pillars of good, namely good for nature, good for human beings, and good for society. Transparent commitment is presented by AQUA Group in the official website on news publications and special sub menus of sustainability.

The development of cyber information technology makes it easier for stakeholders to gain access the communication of CSR, one of which is by utilizing the official website as accurate CSR information. AQUA Group utilizes the potential of the website as one of cyber CSR communication media has a role to put forward the expectations of stakeholders in meeting the needs of information related to CSR and responding to the interests of trusted and accurate stakeholders. Through the official website, AQUA Group was awarded the best corporate website category in the PERHUMAS Excellence Award 2019. AQUA Group shows that the official website of www.aqua.co.id is considered to have a high ability to function and the role of public relations in disseminating positive news, innovation changes, and benchmarking (sustainability assessment related to compliance with laws and norms) related to CSR programs (https://aqua.co.id/).

The purpose of this research is cyber CSR communication conducted by AQUA Group through the official website of aqua.co.id as an object of research to find out as the company optimizes the utilization of cyber CSR communication media for long-term corporate sustainability. Researchers will dig up data and analyze cyber CSR communications conducted by AQUA Group companies through the official website www.aqua.co.id.

The focus of the research is on the content of CSR messages communicated by AQUA Group through the company's official website. Researchers also examined the form of information presentation in conveying the content of CSR messages, and CSR communication patterns established on the official www.aqua.co.id website using content analysis by formulating the following problems: (1) How is the content of cyber CSR messages communicated through the official website www.aqua.co.id?; (2) What is the form of presentation of cyber CSR information communicated through the official website www.aqua.co.id?; (3) What is the pattern of cyber CSR communication communicated through the official website www.aqua.co.id?

Rusdianto (2013:7-8) explained that CSR is a form of business that not only concerns the company's profits, but the company must also pay attention to the interests of others in maintaining the sustainability of the company's life so that the company is required to engage in the social dimension and pay attention to social impacts.

CSR is defined as the social obligation of an organization to the community or stakeholders. Rachman et al. (2011: 17) in his book entitled Complete Guide to CSR Planning as citing the definition presented by ISO 26000, CSR as a form of corporate responsibility for consistently contributing and paying attention to the expectations of stakeholders in the development of sustainability and community welfare in accordance with applicable laws and international norms that are integrated and transparent in all corporate activities towards society and the environment.

International Organization for Standardization (ISO), ISO was compiled as a guideline for social responsibility for the implementation of international standard CSR. ISO is an international standardization organization as a guideline for the implementation of CSR integrated in the guidelines and standardization of social responsibility referred to as ISO 26000. There are seven main CSR issues in ISO 26000 consisting of components of concern by each organization including the company in managing the policies and implementation of the practices of CSR programs, namely: Corporate Governance, Human Rights, Labor Activities, Environment, Fair Operations Activities, Consumer Issues, Contributions to Communities and Communities. (Rachman et al., 2011: 39) 
Implementation model in implementing corporate CSR programs, according to Saidi and Abidin in Rusdianto (2013:14) there are four CSR models applied in CSR programs. The four models are: Direct Involvement, Through Foundations or Social Organizations, Partners with Other Parties, Supporting or Joining a Consortium.

CSR communication of each company is required to have an effective communication understanding to shareholders and stakeholders of the company itself. Rusdianto (2013:21) said that CSR communication is an effort of a company in conveying messages related to the company's commitments, policies, programs and performance in economic, environmental and social pillars to stakeholders.

CSR communication serves to be the main thing in the implementation of CSR implementation. Some experts and researchers explain the definition of CSR communication. According to Nwagbara and Reid (2013: 401) provides an understanding that CSR communication is a process of adjusting stakeholders' understanding of CSR policies and communication tools of a company designed to provide correct and transparent information about the company's integrated business operations, environmental attention, and interaction with stakeholders. Rusdianto (2014: 103) explained that public relations conduct communication with the aim of creating an effect, namely corporate image to foster good relations between the company and the public.

Rusdianto (2013:89) explained that stakeholders in the company's reputation is one of the important elements in CSR communication so that the company provides benefits in building a sustainable reputation by managing CSR communications effectively so that the company avoids a crisis. CSR communication is managed with a planned, directed and carried out in a sustainability manner to stakeholders in order to build a good corporate reputation.

Rusdianto (2013:30) explained that the company should be developed using a basic CSR communication strategy with a corporate communication strategy model. The corporate communication strategy model explains that the communication process that occurs is continuous with each other.

"The Company conveys information related to the implementation of CSR that has been implemented, while stakeholders can provide responses or responses as a form of feedback to companies related to information submitted by the company" (Rusdianto, 2013: 30-31).

The rapid development of information technology, online media is visited by the public if they want to know more about a company. In today's digital age, various studies in communicating CSR are conducted with electronic media that can be used and selected by companies. According to Hidayat in his book entitled Media Public Relations (2014:95) states that cyber CSR is the company's communication strategy in conveying information related to corporate CSR to stakeholders through internet information technology.

Rusdianto (2013: 57) explained that there are many media that companies can choose in CSR communication, namely: internal media (Public Relations, CSR reports, internal magazines, websites, social media and others) and external media (mass media and word of mouth). The diversity of these channels is used to improve the effectiveness of the delivery of a message to diverse stakeholders. The management of CSR communication media in building relationships between companies and corporate stakeholders is the most important part.

Nwagbara and Reid (2013: 407) explain that organizations in creating sustainability and managing reputation through CSR communication across a variety of communication channels that stakeholders can read, understand and interpreted.

\section{RESEARCH METHOD}

This research uses a qualitative method of content analysis with a post-positivism paradigm. Qualitative research with the paradigm of post-positivism not only talks about what is visible, palpable or felt, but also understands the meaning behind a reality. According to Kriyantono (2006:247) stated that qualitative content analysis is a method of more in-depth analysis and also detail in order to understand a media content product and be able to connect it with the reality that existed when the message was made. Qualitative content analysis using categorization techniques where this technique is only used as a guide so that other concepts and categorizations can appear during the research process.

The object of this research is cyber CSR communication in AQUA Group Company through the official website. This research discusses cyber CSR communication using official websites related to corporate CSR conducted by AQUA Group. Cyber CSR communication is divided into three specific sections, namely analysis of message content related to CSR, analysis of CSR information presentation, and analysis of CSR communication patterns on aqua group official website.

The research subject of this research is the official website of AQUA Group Company namely www.aqua.co.id. Official Website is a reference for researchers in obtaining accurate information and become research materials that are analyzed in more depth.

The author chooses www.aqua.co.id which is the official website of AQUA Group as the research location. This www.aqua.co.id is where the actual state of the object makes it easier for researchers to obtain data to study in-depth analysis. 
Table 1 RESEARCH ANALYSIS UNIT TABLE

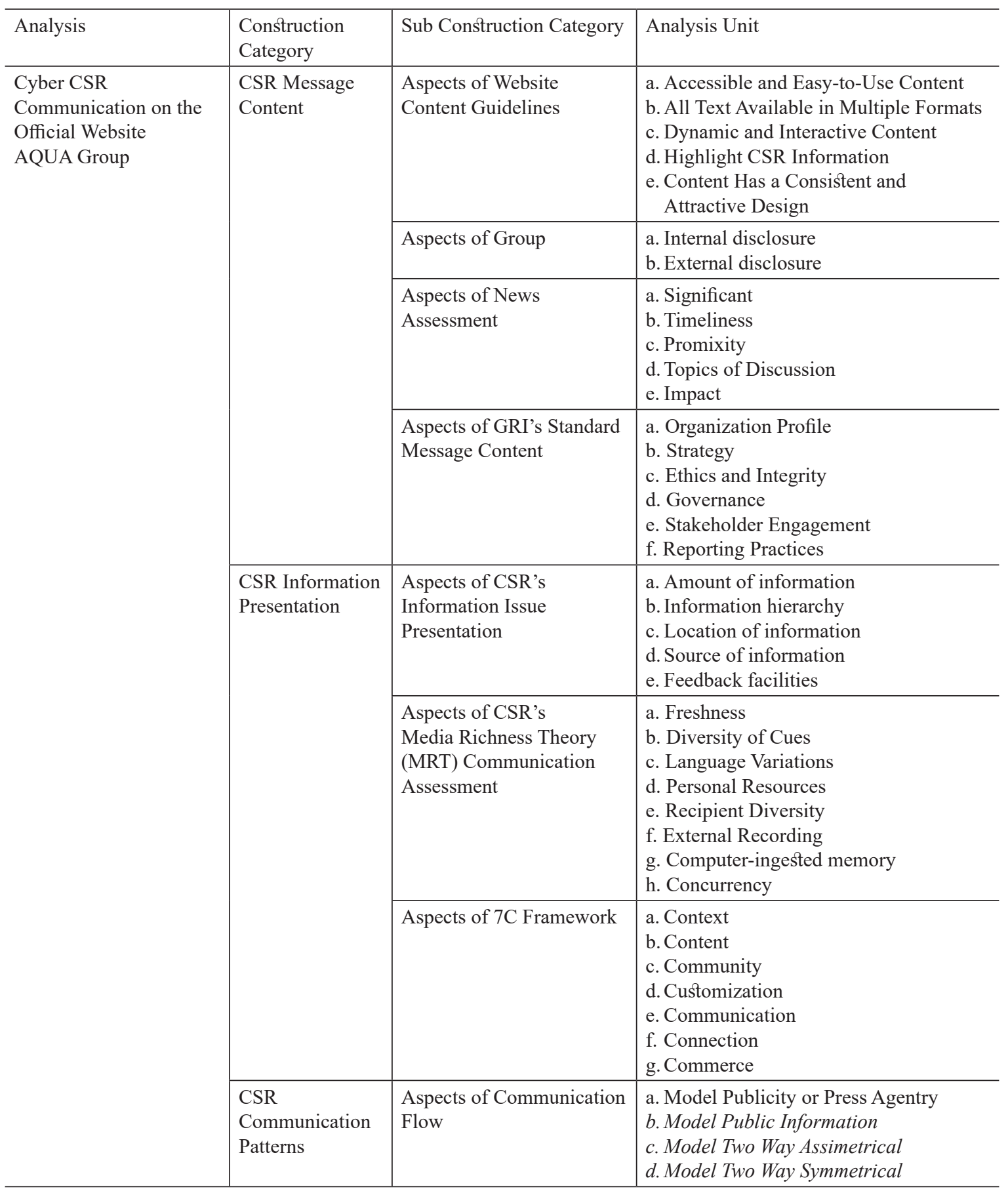

Source : Processed by Researchers (2019)

Data collection is used by documentation study techniques in accordance with research objectives. Data analysis techniques in this study with three stages, namely data immersion stage (research involvement with data), data reduction stage (developing consistent approach to data), and data interpretation stage. The data validity technique in this study uses persistence of observation and theoretical triangulation. Researchers attempted to use several theories to compare the findings of data obtained by researchers to strengthen the arguments of researchers.

\section{RESULTS AND DISCUSSION}

Researchers interpreted with a documentation study of 40 content of CSR cyber messages on the official website of AQUA Group with eight CSR-specific sub-menus. The researchers presented the findings of data that the content of CSR messages displayed on the official website of AQUA Group in accordance with the five guidelines for publishing 
website content by Coope (2004) in Rusdianto (2014:124-127) to find out the purpose of CSR communication. The results of the data analysis showed that the official website of AQUA Group as one of the channels to distribute CSR content has optimal content quality and meets all five guidelines for publishing website content.

The first guideline is that content is accessible and easy to use. Content can be accessed through mobile electronic devices or computer devices by audiences or stakeholders with the aim of helping audiences easily find and receive CSR messages. Help navigate menu features clearly and briefly with the aim of assisting the audience in meeting the needs of CSR information needed. Visual images and writing with clear fonts and white on a blue base with the aim of helping a special audience that has limited vision capabilities.

The second guideline is the text displayed in the form of the official website www.aqua.co.id using HTML and PDF formats. HTML format with easy-to-understand homepage view and PDF format that can be downloaded by audiences or stakeholders with the aim of CSR communication offers for audiences or stakeholders to download the required information, such as award reports or sustainability reporting.

The third guideline is content that in this CSR-specific sub-menu is also dynamic and interactive because there are social media address links, call centers, and message boards that are connected so that audiences for CSR communication purposes can provide feedback in response to the message displayed by the website.

The fourth guideline is CSR information that is highlighted also clearly, especially in the CSR program carried out by AQUA Group with the AQUA Lestari program that has links and visual images that can be accessed by stakeholders or the public at large, implementation of corporate innovation, and structured corporate governance management.

The fifth guideline is the content displayed is designed with a similar background color to other products and pages or main pages and there are visual images so that it is easy to understand and the writing or color of the writing is designed consistently with a font that can be read well.

The following is the result of the analysis of AQUA Group website content publishing in distributing CSR content presented in the form of scheme figure 1.

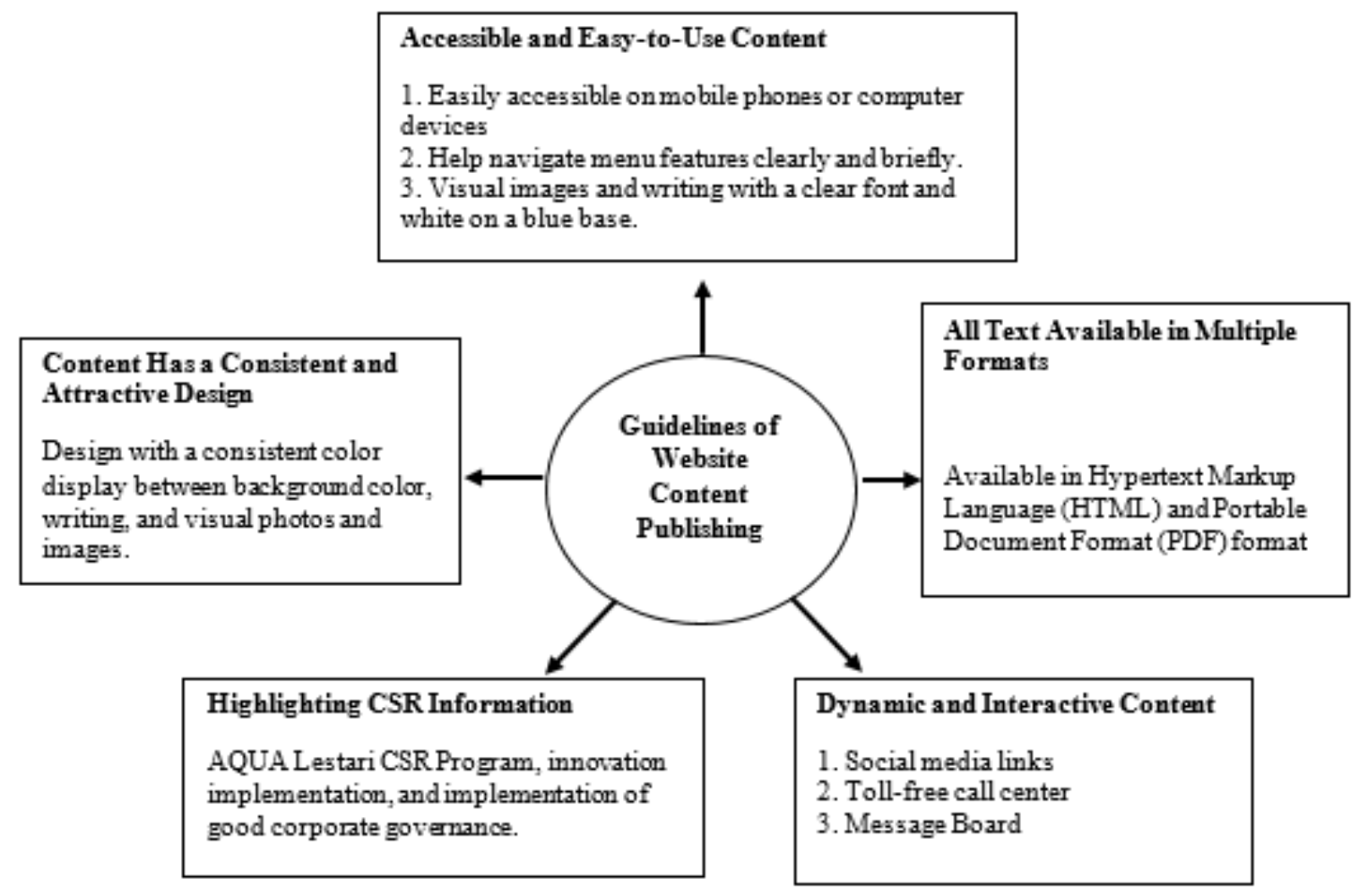

Pic 1. Content Analysis of AQUA Group Website Content Publishing Coope's Concept (2004) cited in Rusdianto (2014:124-127)

Source: Processed by Researcher (2019)

AQUA Group strives in grouping CSR communication against the content of messages contained on the official website to know the content of CSR messages that must be communicated. The data findings show that AQUA Group companies conduct CSR communications with reference to internal and external group disclosures. This is in accordance with the theory of Branco \& Rodrigues (2006: 232-248) which explains the content of CSR messages consisting of 
internal and external groups. The results of the analysis of data findings on the analysis of the contents of the message group, researchers described in figure 2.

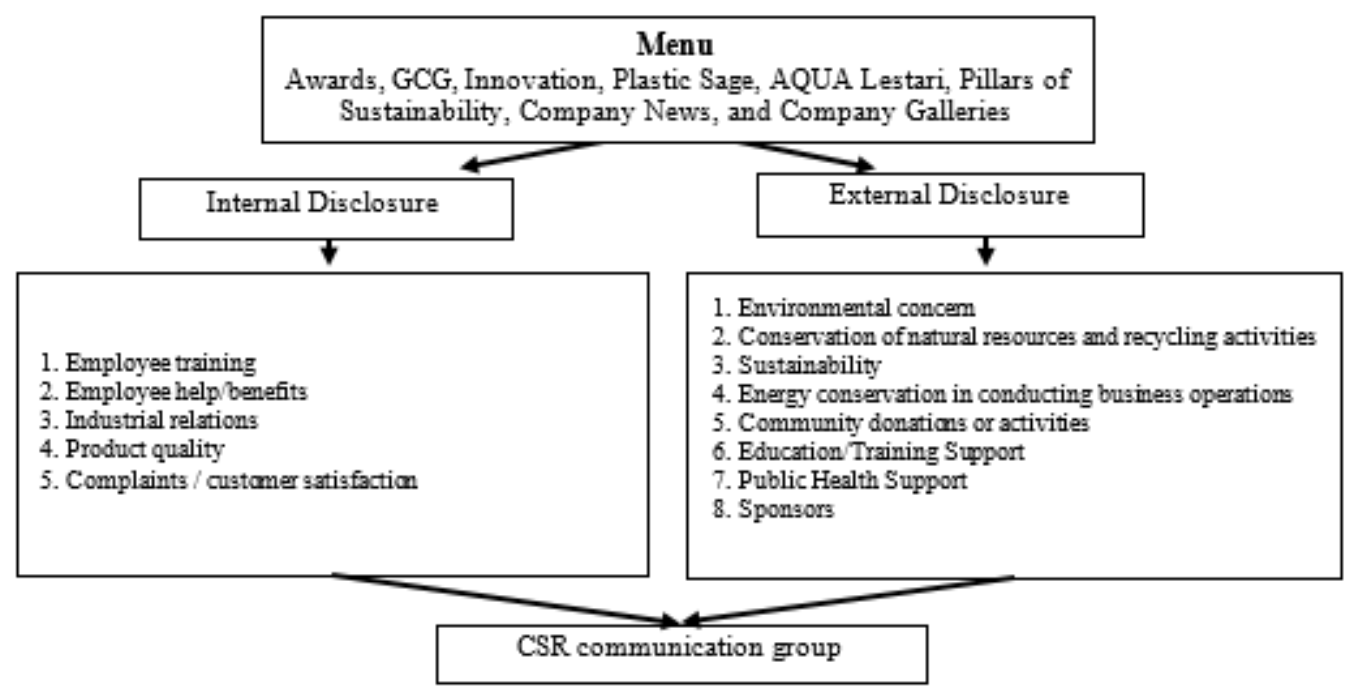

Pic 2. Content Analysis Group Message AQUA Group Website Concept of Theory Branco \& Rodrigues (2006: 232-248) Source: Processed by Researcher (2019)

Based on the scheme picture above, researchers analyzed 55 CSR-related message content with eight CSR-specific sub-menus and fifteen news related to CSR on the AQUA Group official website. Researchers obtained the results of the analysis that through the official website of AQUA Group showed that 40 CSR messages consisted of external groups covering the environment and involvement in the community or community, while the internal group covering human resources, products, and customers only got 15 CSR messages. This indicates that AQUA Group pays special attention to external disclosure with concern for the environment, and the company's involvement with the community. Rusdianto (2013:48) explained that the content of the CSR message should explain the level of corporate involvement in CSR activities by emphasizing one or more of the following factors: commitment, impact, motive and in accordance with the target group. AQUA Group Company in CSR activities by emphasizing the commitment to environmental care.

Aqua Group's involvement in the community is also one of the company's responsibilities in the implementation of CSR based on seven main issues of ISO 26000 by Rachman et al. (2011: 39) contribution category or local communities and around the AQUA plant and environmental improvement categories in line with AQUA's business operations in responding to social, economic, and environmental impacts.

AQUA Group in the internal disclosure group on CSR message content communication in the official website only focuses on employee training in corporate governance, especially training in structured direction Danone Governing and Operating Process, employee benefits for the company's operating performance is awarded, inter-party industrial relations, product quality for public health, and customer satisfaction level of trusted brands.

AQUA Group indicates that the company through its official website is not transparent in informing human resources, especially information regarding the health and safety of employees, minority employees, employee remuneration, employee profiles, employee purchase schemes, and employee morale. Information about human resources is only published publicly on sustainability reports and about the company's finances is not transparent because aqua group company is a closed company so AQUA does not disclose financial data to the public.

AQUA Group's official website does not refer to the principle of transparency as a corporate CSR communication tool designed to provide transparent information about business operations to AQUA Group stakeholders. As it is said that a company's CSR communication tools are designed to provide correct and transparent information about the company's integrated business operations, environmental attention, and interaction with stakeholders (Nwagbara and Reid, 2013: 401).

News from AQUA Group Company can be a CSR communication need for stakeholders, especially with accurate sources and wide accessibility. AQUA Group ceases to share and bring good news for stakeholders in providing communication, especially in the field of CSR as the company's efforts in publishing messages to stakeholders related to 
commitments, CSR program policies, and the performance of AQUA Group companies in the economic, environmental and social fields. This is in accordance with Rusdianto (2013:21) that CSR communication as the company's efforts in conveying messages related to the company's commitments, policies, programs, and performance in economic, environmental and social pillars to stakeholders.

AQUA Group realizes the existence of stakeholders so as to communicate CSR effectively to stakeholders through news publications in order to build a reputation for the company's sustainability in order to avoid a crisis. AQUA in the publication of news message content pays attention to several factors for the realization of effective communication, this is in accordance with (Rusdianto, 2013:89) that CSR communication must be planned, directed, and run in a sustainable manner to stakeholders, in order to create a corporate reputation.

The contents of the news message explain that the content of the CSR message should explain the level of involvement of AQUA Group in CSR activities by emphasizing one or more of the following factors: commitment, impact, motive, and in accordance with the target group.

Researchers analyzed fifteen CSR news from 44 news in the period January 2018 to January 2020 that were adjusted to the period of sustainability reporting to the latest news. The factors that researchers analyze are related to commitments with fact sheets of CSR news content, CSR message content groups, CSR target targets, CSR related issues by ISO 26000, CSR motives consisting of corporate problems and engagement, and CSR news values. Here researchers scheme the contents of CSR news messages through the official website of AQUA Group in figure 3.

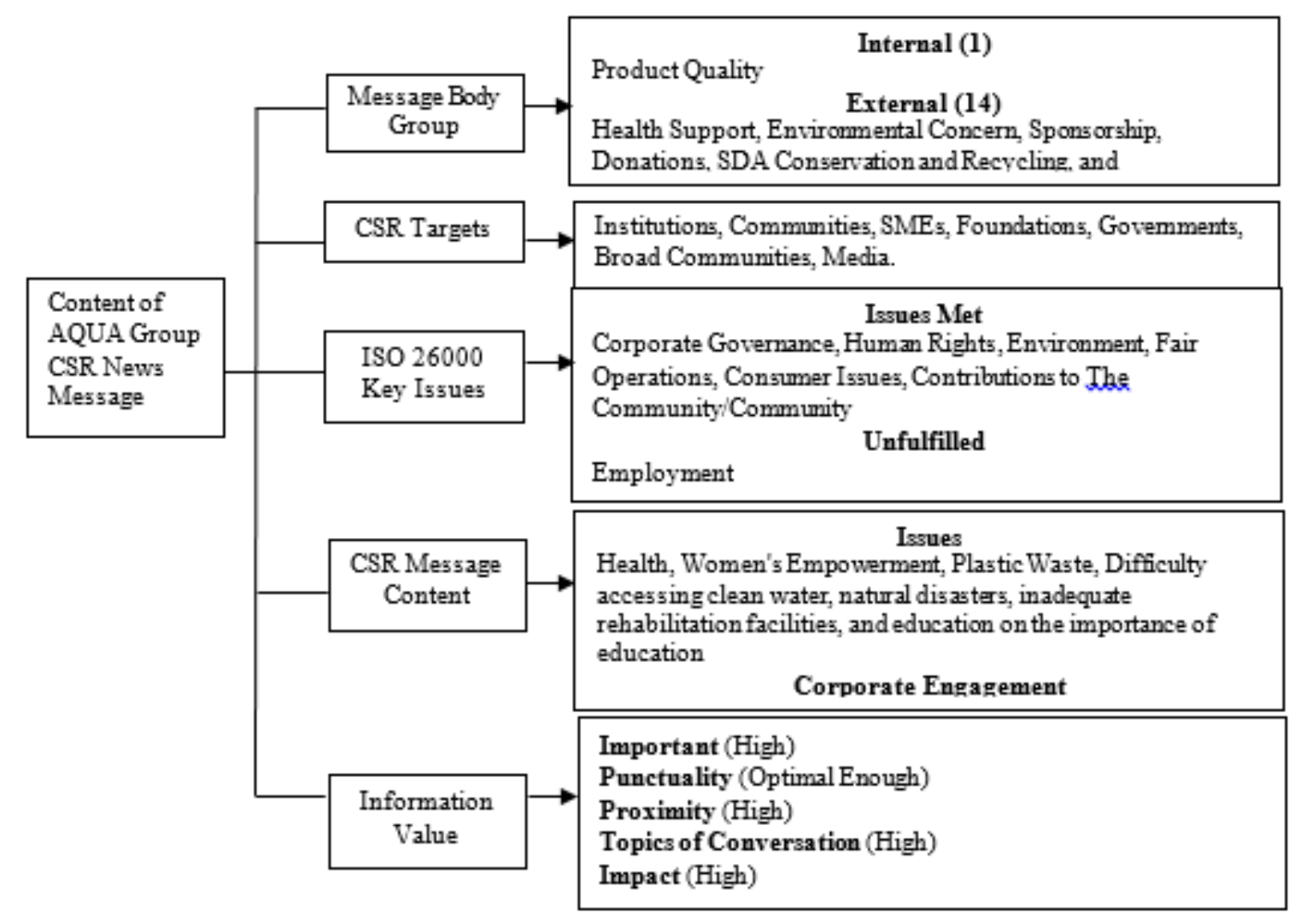

Pic 3. Analysis of CSR News

Content on AQUA Group Website

Source: Processed by Researcher (2019)

The data findings show that AQUA Group companies pay attention to the content of news messages that become CSR cyber communications. News published by AQUA Group has sought to fulfill the values of the news into a news that is feasible and optimal enough to be read by the public. This is in accordance with five news values by Rusdianto, 2014:198-199, namely important values, timeliness, proximity, topic of conversation, and impact. The punctuality value of the news published by AQUA Group has not been realized to the maximum, there are five news that have delays in publication. This becomes an evaluation material for AQUA companies in communicating related to The AQUA Group CSR issue. 
The content of AQUA Group's news message explains that AQUA has contributed to be involved in trying to solve social problems that occur in the middle of local communities or the wider community. Aqua Group's involvement in accordance with the CSR model presented by Rusdianto 2013:14 states that the company carries out its social activities in cooperation with other parties. AQUA Group conducts CSR programs by partnering with other parties such as cooperating with institutions, foundations, communities, governments, or UMKM in implementing CSR programs.

AQUA Group has tried to resolve CSR issues in accordance with ISO 26000 properly, but there is one issue that is not met published by AQUA Group, namely about labor or employment activities which is one of the important elements that need to be considered both from employee health, safety and safety and remuneration received by employees. This is because AQUA on an organizational scale is closed so that the company's internal financial data has a confidential nature.

AQUA Group in communicating CSR programs not only on news publications. The company also communicates CSR through sustainability reporting (sustainability report). Researchers analyzed components based on the GRI-102 GSBB 2016 reporting guidelines. The analysis of the data findings that researchers conducted on the sustainability report downloaded in PDF format on the official AQUA Group website shows that the company has attempted to communicate information in accordance with the standards in the GRI 102 GSBB 2016 sustainability reporting guidelines in reporting the economic, environmental, and social impacts on AQUA Group stakeholders regarding the contribution of CSR activities to corporate sustainability. This is in accordance with the definition (GRI 102, 2016) GRI is a sustainability reporting standard designed for use by organizations in reporting economic, environmental, and social impacts on stakeholders. However, overall AQUA Group does not put forward the principle of transparency in reporting information on CSRrelated issues, especially in two guidelines, namely the ethical guidelines of integrity and corporate governance.

AQUA Group does not communicate all information indicators transparently to stakeholders which is the main value of CSR communication aspects. As (GRI G-3.1, 2011: 5-6) states that GRI explains that transparency is the main value that is the basis of all aspects of CSR communication. AQUA Group communicates CSR-related issues in GRI reporting on the official website only as a symbol of the company's compliance with stakeholders. Researchers present the results of the analysis in the picture below.

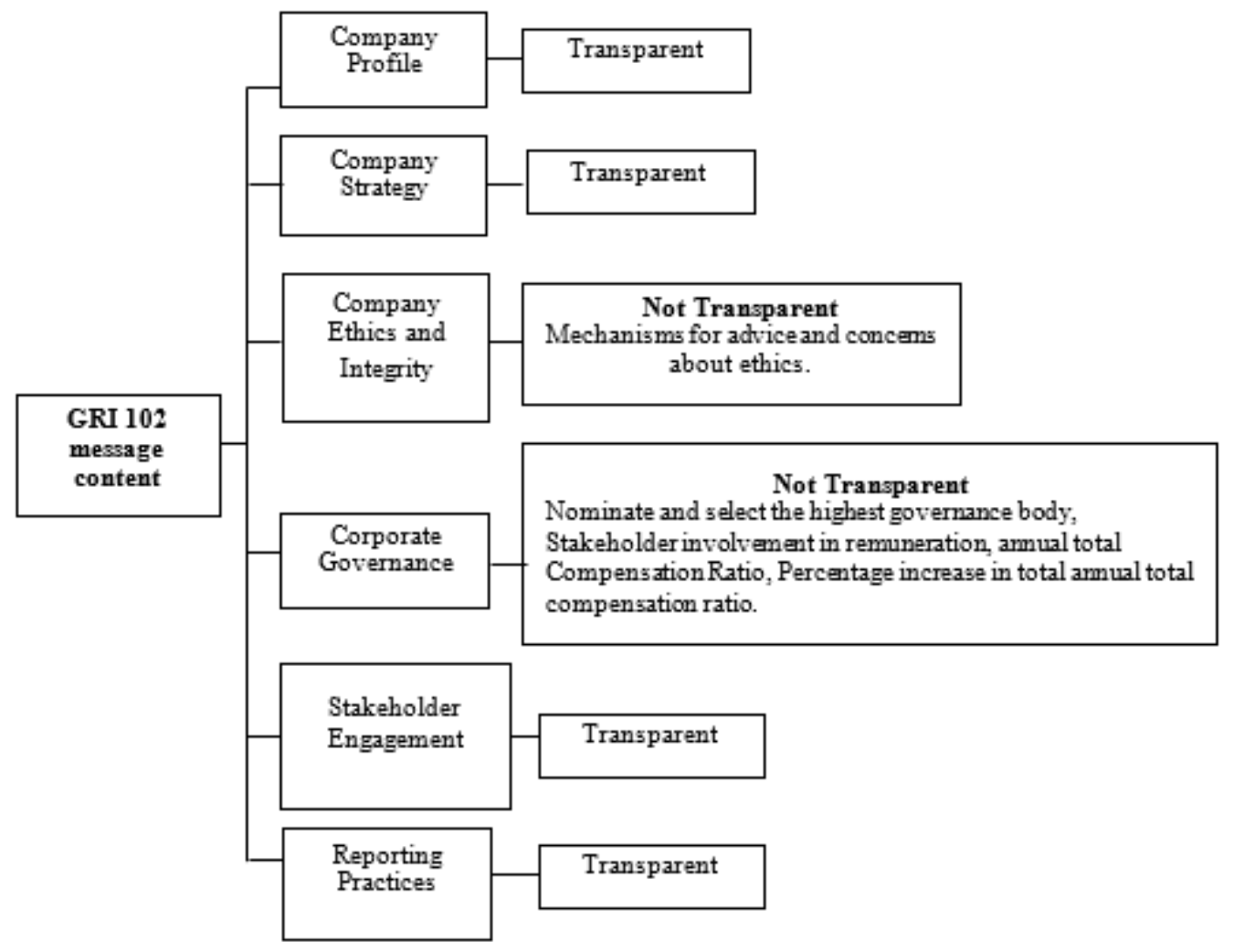

Pic 4. Content Analysis of GRI Sustainability Reporting Message GRI Theory Concept 102 GSBB 2016

Source: Processed by Researcher (2019)

Researchers interpreted the presentation of AQUA Group cyber information on CSR-related issues on the company's official website. According to Capriotti and Moreno (2007: 84-91) in Rusdianto (2014:164-165) there are ten CSR-related issues displayed on the company's official website. AQUA Group has attempted to convey comprehensive 
information on the fulfillment of ten CSR-related issues in the company's official website. The presentation of information on issues related to CSR AQUA Group is divided into five categories, namely the amount of information, hierarchy of information, location of information, sources of information, and feedback facilities in accordance with the theory of Harmony, 2009: B59. The results of analysis on the presentation of information related to CSR issues as a media of cyber CSR communication on the official website of AQUA Group are classified as presented quite optimally.

The category of information on the official website is optimally communicateable and has fulfilled ten CSRrelated issues. The category of information hierarchy presents an optimal message and a special majority towards the three basic principles of triple bottom lines for the sake of corporate sustainability. This indicates that AQUA Group is paying attention to the importance of CSR information to stakeholders and the public.

The category of location information is not optimally located in a separate menu in the official website of AQUA Group. AQUA Group does not pay special attention in managing the menu well to be presented to stakeholders. The public or stakeholders cannot reach more in-depth in looking at and looking for CSR information needs on the official AQUA website.

The category of information sources is presented optimally on the official website with the availability of multimedia graphic animation and hypertext so that the public becomes active and participatory in seeking CSR information needs.

The category of feedback facilities is presented optimally by the official AQUA website so that stakeholders or the public can evaluate programs related to CSR issues. This indicates that AQUA Group gives special attention to stakeholders and the public to respond or interact regarding CSR issues to AQUA companies.

Researchers described the scheme of data findings analysis on the presentation of CSR information issues on the official aqua group website as follows.

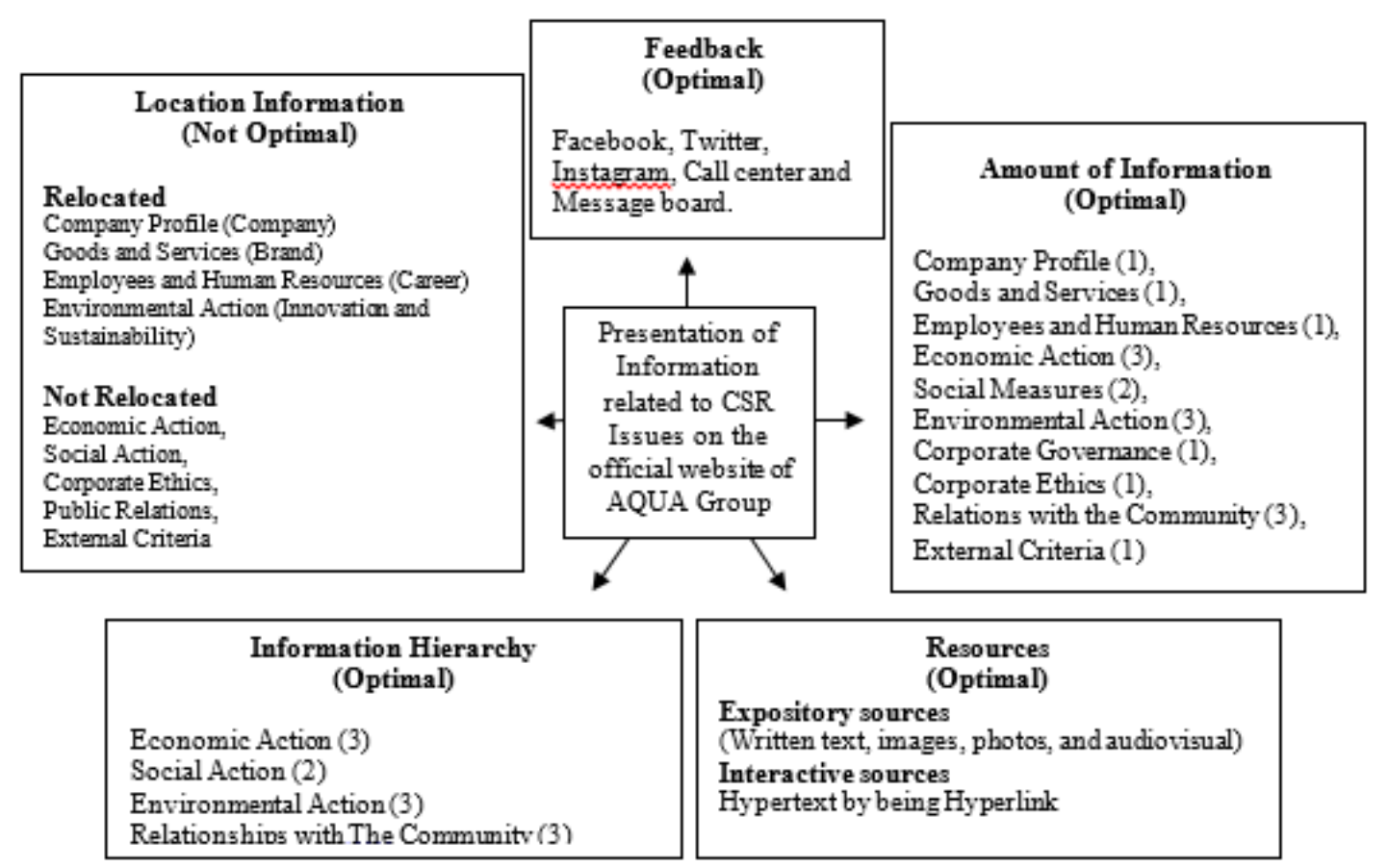

Pic 5. Analysis of CSR Issue Presentation

Concept of Harmony Theory 2009: B59

Source: Processed by Researcher (2019)

Researchers analyzed CSR communication assessment on AQUA Group official website using eight criteria of Media Richness Theory (MRT) Lodhia (2006:65-94) namely: freshness, diversity of cues, variety of language, personal source, recipient diversity, external recording, computer-filled memory, and concurrency. The results of the analysis of CSR information presentation on the official website of AQUA Group related to the assessment of communication of MRT criteria showed that the information presented was considered quite optimal in facilitating CSR communication needs. AQUA Group companies show not fully utilizing the potential of official websites extensively. The efforts made by AQUA Group are considered not maximum because there are several criteria that are not available in the completeness of the information facilities presented.

The freshness feature through the data findings shows that there are no live streaming criteria available on the official AQUA website in implementing CSR-related issues. AQUA is considered to only attach photo uploads to news publications as a tangible manifestation of having implemented CSR programs to stakeholders. 
The recipient diversity feature, AQUA Group provides wide access to stakeholders to meet information needs, but this feature is not available push-based notification facilities to stakeholders. This shows that AQUA Group has not maximized the official website facilities in meeting information needs extensively.

External recording features through data findings show no hit counters and electronic guestbooks as a facility to track how many stakeholders access official websites and access CSR information. Data archives regarding sustainability reports in the previous period were also not available on the official website so stakeholders could not reach the information in depth. This shows that the unavailation of hit counter features and data archives become evaluation material in optimizing official website facilities as the fulfillment of information needs to the maximum for stakeholders.

Computer-filled memory features through all data results show the unqualified sitemap, web table of contents, and analytics features that are some of the important features in the presentation of CSR information on the web in making it easier for stakeholders to meet their information needs. AQUA Group only focuses on navigation facilities, paying less attention to the potential of official websites in fulfilling the completeness of information servings to facilitate stakeholders.

AQUA Group in the official website has tried to utilize the potential of the website as a wealth of media in presenting information related to CSR. However, AQUA Group has not utilized the official website to the maximum and extensive in improving accessibility and interactivity to all stakeholders and the public to meet the needs of information related to CSR. It is in accordance with Lodhia's theory (2006:65-94) that AQUA Group views the website only as a liaison between the company and stakeholders or the public alone, the company has not maximized the presentation of official website information as a presentation tool and important information, especially as a form of CSR communication media.

AQUA Group has a high level of interactivity to information fulfillment facilities, but the level of accessibility is considered relatively low. This is because AQUA Group is considered as a closed company on an organizational scale. This reason becomes a limitation in the accessibility of official websites at large. Lodhia (2006:89) stated that the company does not want to use the official website optimally as a CSR communication media is due to the issue of limited access to some stakeholders, confidentiality and security issues, concerns about excessive information, to the costs required to manage the official website.

Researchers presented the results of analysis of CSR communication assessment related to the presentation of information in the picture below.

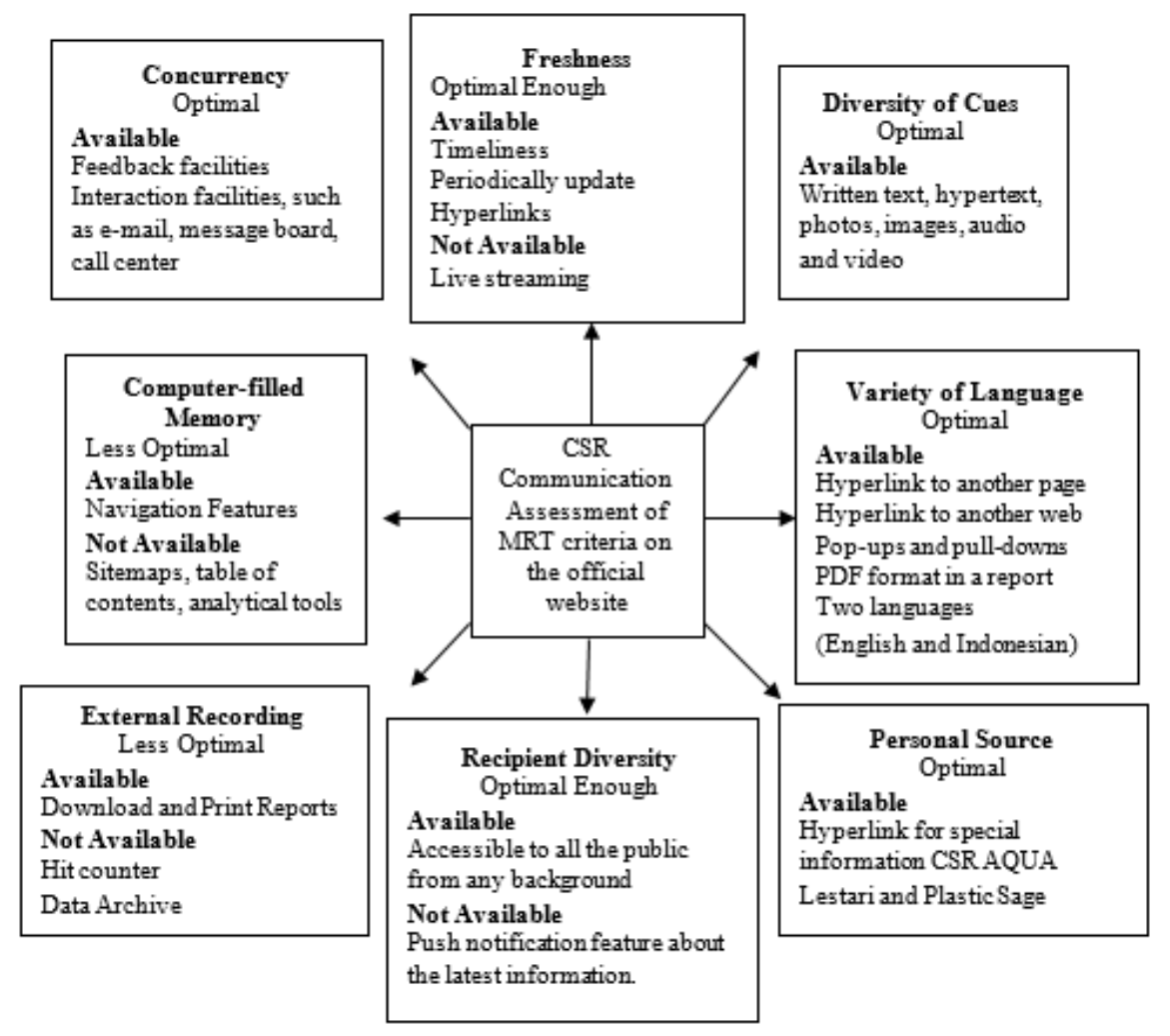

Pic 6. CSR Communication Assessment Analysis of MRT criteria Lodhia MRT Theory Concept (2006:65-94)

Source: Processed by Researcher (2019) 
Researchers analyzed the assessment of virtual representation of CSR communication on the official website of AQUA Group by using seven elements of 7C framework theory in designing the presentation of CSR-related information. According to Rayport and Jaworski (2003: 154-182) there are seven elements in 7C's framework, namely context, content, community, customization, communication, connection, and commerce. Researchers presented the results of analysis of the assessment of virtual representations of CSR communications in designing the presentation of CSR information in figure 7 .

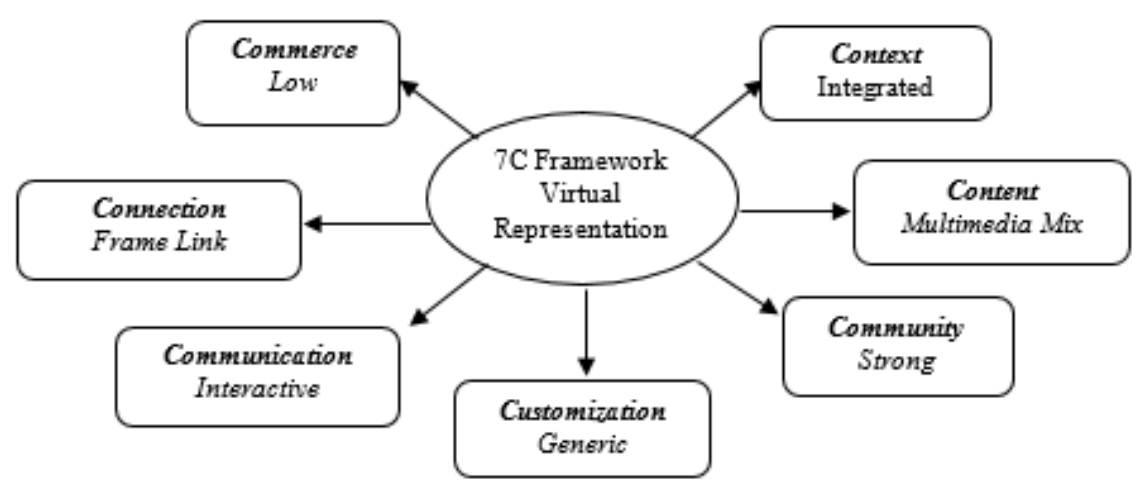

Pic 7. Virtual Representation Assessment Analysis 7C Framework Theory Source: Processed by Researcher (2019)

Based on the scheme of analysis results above, AQUA Group has attempted to design a business model through the company's official website, but the company still does not pay extensive attention to the implementation of the business on the official web. AQUA Group does not utilize the potential of the website extensively in supporting the marketing of the company's product business. This is supported by Rayport and Jaworski theory (2003:150-151) states the $7 \mathrm{C}$ framework is a framework designed for virtual representation of the values that companies use in implementing their business in web marketing.

AQUA Group is considered to have a high virtual representation of aesthetics and is informative in presenting information on the official website. AQUA Group integrates into exotic values and functional values combining multimedia graphic animation with AQUA product or information offerings.

AQUA Group is content is considered to refer to multimedia mix and pay special attention to the display of information visualization by combining text, audio, images, video, and graphics. AQUA is considered context and content is optimal in presenting information on virtual representations of the company's business implementation.

AQUA Group pay special attention to the elements of the community who collaborate and cooperate with the company. AQUA's involvement is considered strong in interactive to its corporate community, especially in official websites with a message board for the implementation of the company's business success. The communities that collaborate with AQUA Group, namely the plastic sage community, the food revolution movement community, the Community Management System for Drinking Water and Sanitation (KP-SPAMS), the AQUA home service community, and AQUA Lestari's friends.

Virtual representation on customization elements through the official website of AQUA Group is considered generic by displaying the presentation of similar information between the company to the public and stakeholders. AQUA Group has not maximized the website's potential extensively in managing user-friendly customizations to the company's web pages.

AQUA Group in implementing business in the company's official website is considered interactive with a form of two-way communication to the public or stakeholders through call centers, e-mails, social media, and message boards. AQUA Group is considered to refer to framed links that display important linked sites in the official website, namely plastic sage sites and aqua sustainable sites.

AQUA Group is considered not to implement the business in a commerce way in the official website. Official website does not have functional e-commerce so AQUA Group is rated low in web design especially towards the presentation of information. There are no functional features in the form of registration, shopping cart, credit card approval, order tracking, and shipping options, but AQUA Group provides a message board on the AQUA Menyapa menu feature for product purchase and ordering categories.

Overall, in representing virtual in designing the website as a business implementation by AQUA Group is considered not optimal. This becomes the evaluation of the company in utilizing the potential of the website extensively as a web marketing that favors drinking water packaging products. Not only focus on information, but AQUA Group should pay special attention in web design in implementing AQUA product business that has been established since 1973 on the official website www.aqua.co.id. 
AQUA Group is paying attention by creating dialogue interactions with CSR-related stakeholders through its website. AQUA builds CSR communication by involving stakeholders in order to build perspective equations on information presented through the website.

AQUA Group strives to build trust by responding to demands and listening to stakeholders' expectations of the required information or information displayed through the official website of the AQUA Menyapa feature (consisting of social media facebook, twitter, Instagram, youtube, call centers and message boards). This is in accordance with the theory (Rusdianto, 2014:126) that the website offers an opportunity for organizations to respond to the demands of stakeholders, and communicate the company's values through CSR communication and provide an excellent basis for engaging stakeholders in order to realize the success of CSR communication. However, the response built by AQUA Group to stakeholders is not visible to the public because AQUA Group on an organizational scale is closed in order to maintain the security of corporate secrets, especially the response to the company's internal data information needs.

Analysis of information presentation conducted by researchers shows that AQUA Group has a high level of interactivity to information fulfillment facilities, especially in feedback facilities. This indicates that aqua group uses symmetrical two-way communication pattern (two way symmetrical model). Here's the scheme of communication patterns used.

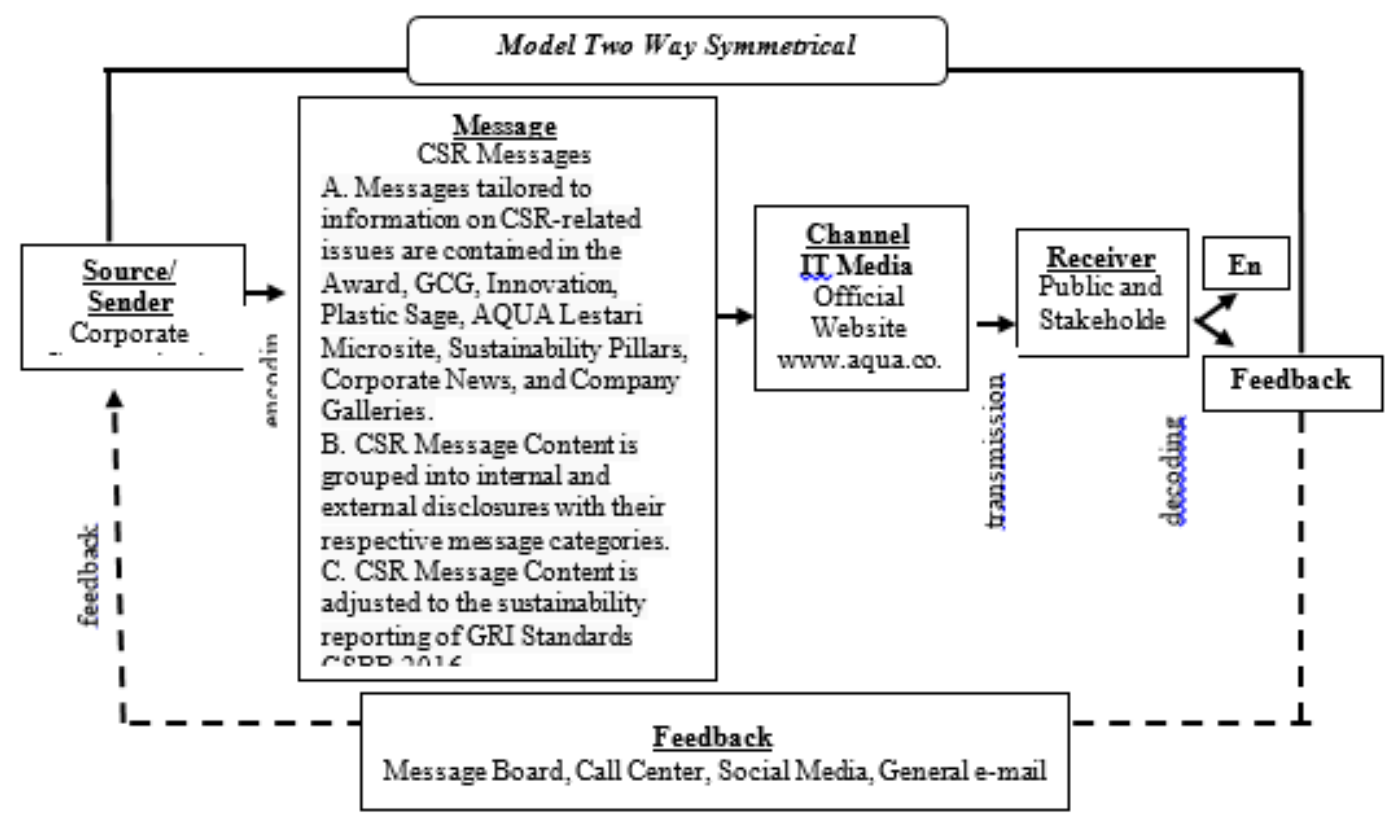

Pic 8. Analysis of CSR Cyber Communication Patterns on AQUA Official Website Source: Processed by Researcher (2019)

Based on the scheme of the picture above, the communication process built by AQUA Group runs in a twoway way between the company and stakeholders with the ambiance as an informer or recipient of information related to CSR. Stakeholders convey feedback as a form of CSR communication related to the presentation of AQUA Group CSR information through the website. This is in accordance with (Rusdianto, 2013: 30-31) that the company conveys information related to the implementation of CSR that has been implemented, while stakeholders can provide responses or responses as a form of feedback to the company related to information submitted by the company.

Researchers see the communication process built by the company is virtual interactively so that it has the impact of a two-way patchy relationship that is balanced with the availability of message boards, call centers, social media, and general e-mail between stakeholders and aqua group corporate communication parties. This two-way communication pattern is able to avoid conflicts or solve conflicts that occur in misperceptions by improving the understanding of stakeholders and the public to build mutual understanding and support for both parties. It is in keeping with Grunig and Hunt's theory (1984) in Rusdianto (2014:105) that the two-way symmetrical model is able to solve and avoid conflict by improving public understanding to build mutual understanding of support and benefit for both parties.

\section{CONCLUSION}

The content of cyber CSR (Rusdianto, 2014:198-199) messages communicated by AQUA Group through the official website has attempted to distribute the contents of the message in accordance with the five content publishing guidelines, meets seven main issues of ISO 26000, news message values, and in accordance with the GRI 102 GSBB 
2016 reporting guidelines in reporting CSR-related messages in order to create a good reputation for building long-term sustainability. The content of the CSR message communicated by AQUA Group through the official website indicates that AQUA Group has referred to the principle of overall transparency as a corporate CSR communication tool designed to provide transparent information about business operations to stakeholders. However, the content of the message related to internal disclosure of human resources and employment issues containing categories of employee health, safety and security, and remuneration received by AQUA Group employees is considered not transparent because AQUA is a closed company so it does not disclose financial data to the public.

The presentation of CSR cyber information communicated (Lodhia (2006:65-94) by AQUA Group through the official website shows that AQUA Group has a high level of interactivity to information fulfillment facilities, but the level of accessibility is considered relatively low. AQUA Group pay special attention to stakeholders and the public to respond or interact regarding CSR issues to AQUA companies. AQUA Group does not pay special attention in managing the menu so that it is well located to be presented to stakeholders. The public or stakeholders cannot reach more in-depth in looking at and looking for CSR information needs on the official AQUA website. Overall, in representing virtual in designing the website as a business implementation by AQUA Group is considered not optimal as web marketing in trading transactions that favor drinking water packaging products.

Cyber CSR communication pattern communicated (Rusdianto, 2013: 30-31) by AQUA Group through official website shows that AQUA Group uses symmetrical two way symmetrical communication pattern. AQUA Group strives to build trust by responding to demands and listening to stakeholders' expectations of the required information or information displayed through the official website in privacy in order to maintain the company's internal confidentiality. This twoway communication pattern is able to avoid conflicts or solve conflicts that occur in misperceptions by improving the understanding of stakeholders and the public to build mutual understanding and support for both parties.

\section{REFERENCES}

[1] Ali, D.S.F., Arfilia, F., dan Lestari, M.T. (2015). Public Relations Process Managing Twitter Social Media (Descriptive Study on @infobdg Public Relations Program, for the Period of May 2015). Journal of Communication, 4339-4342.

[2] Branco, M. C., \& Rodrigues, L. L. (2006). Communication of corporatesocial responsibility by Portuguese banks A legitimacy theory perspective. Corporate Communications: An International Journal, Volume 11 No.3.

[3] Butterick, Keith. (2012). Introduction of Public Relation: Theory and Practice. Jakarta: PT. Raja Grafindo Persada.

[4] Global Reporting Initiative. (2011). Sustainability reporting guidelines version 3.1. Amsterdam. Retrieved from Global Reporting Initiative: http://www.globalreporting.org/ accesed on November 6, 2019 at 17.44 WIB

[5] Global Reporting Initiative. (2016). GRI 102: 2016 GSBB Standards General Disclosures. Retrieved from Global Reporting Initiative: http://www.globalreporting.org accesed on November 6, 2019 at 18.21 WIB

[6] Harmoni, A. (2009). Interactivity of CSR Issue Official Site of Study Companies at PT Indocement. Tunggal Prakarsa Tbk. National Journal of Gunadarma University Library, B57-B61.

[7] Harmoni, A. (2014). Media Richness Theory and Website Potential as CSR Communication Media By Companies. National Journal of Gunadarma University Library, 2.

[8] Hidayat, Dasrun. (2014). Media Public Relation: Cyber Public Relations Case Study Approach as Digital PR Working Method. Yogyakarta: Graha Ilmu.

[9] Kriyantono, Rahmat. (2006). Practical Techniques for Communication Research. Jakarta: Kencana Prenada Media.

[10] Lodhia,S. K. (2006). The World Wide Web and Its Potential for Corporate Environmental Communication: A Study into Present Practices in the Australian Minerals Industry. The International Journal of Digital Accounting Research, 69-78.

[11] Nwagbara, U., \& Reid, P. (2013). Corporate Social Responsibility Communication in the Age of New Media: Towards the Logic of Sustainability Communication. International Comparative Management, 401.

[12] PUSAKA, S. (2017, Juni 12). Lauch of GRI Standards 2018: Read Directions for Future Accountability. Retrieved from CSR Magazine's Guide to Sustainable Business:https://majalahcsr.id/peluncurangri-standards-2018membaca-arah-akuntabilitasmasa-depan/3 accesed on Oktober 22, 2019 at $15.41 \mathrm{WIB}$

[13] Rachman, N., Efendi, A., \& Wicaksana, E. (2011). Complete Guide to CSR Planning. Jakarta: Penebar Swadaya.

[14] Rayport, J. \& Jaworski, B. (2003). Introduction to E-Commerce. 2nd Edition. New York: McGrawHill.

[15] Rusdianto, Ujang. (2013). CSR Communications A Framework for PR Practitionsers. Yogyakarta: Graha Ilmu.

[16] Rusdianto, Ujang. (2014). Cyber CSR: A Guide to CSR Communications on Cyber. Yogyakarta: Graha Ilmu.

[17] (UU), U.-u. (2007, Agustus 16). Undang-undang (UU) on Limited Liability Companies No. 4- of 2007 concerning Social and Environmental Responsibility of Limited Liability Companies. Retrieved from JDIH BPK RI DATABASE PERATURAN: https://peraturan.bpk.go.id/Home/Details/ accesed on Novemver 3 at 18.45 WIB. 
